\title{
Gamma oryzanol niosomal gel for skin cancer: formulation and optimization using quality by design $(\mathrm{QbD})$ approach
}

Harsh S. Shah' ${ }^{1}$, Ankit Gotecha², Dolly Jetha ${ }^{2}$, Amarjitsing Rajput ${ }^{3}$, Aditi Bariya ${ }^{4}$, Shital Panchal ${ }^{*}$ and Shital Butani $i^{2^{*}}$ (1)

\begin{abstract}
Skin cancer is fifth most diagnosed disease in human population due to ultraviolet radiation (UV) exposure. Gamma oryzanol $(\mathrm{OZ})$ is a natural antioxidant, and it also has skin anti-aging properties. OZ is naturally found in rice bran oil. The main aim of the present work was to optimize OZ niosomal formulation using quality by design approach including one variable at a time and full factorial design. Niosomes were prepared by solvent injection method and characterized for size, polydispersity index, drug entrapment, and transmission electron microscopy. The optimized batch obtained at $X_{1}$ [drug to span 60 molar ratio (1:5)], $X_{2}$ [volume of hydration $(75 \mathrm{~mL})$ ], and $X_{3}$ [stirring speed (2500 rpm)] to $Y_{1}$ [average vesicle size $(196.6 \mathrm{~nm})$ ] and $Y_{2}$ [entrapment efficiency $(78.31 \%)$ ] as dependent variables. The optimized OZ noisomes were formulated by niosomal gel to provide improved physicochemical stability upon topical application against UV. The niosomal gel was characterized using pH meter, viscometer, Draize test for skin irritancy, ex vivo permeation studies, and stability studies. Ex vivo permeation studies of OZ niosomal gel not only showed fourfold higher permeation but also exhibited better drug retention in dermal layers of skin as compared to OZ gel. Quality Target Product Profile of OZ niosomal formulation was generated. Risk analysis of optimized OZ gel suggested most critical quality attributes (CQAs) and critical process parameters (CPPs) to be characterized as low risk. Thus, $\gamma$-oryzanol niosomal gel for topical use can serve as a promising prophylactic treatment in skin cancer, and the developed prototype formulation can be further extended to future newly discovered drugs with similar characteristics.
\end{abstract}

Keywords: Niosomes, Niosomal gel formulation, Quality by design, Quality target product profile, Risk assessment

\footnotetext{
*Correspondence: shital.panchal@nirmauni.ac.in; shital.butani@nirmauni.ac.in

2 Department of Pharmaceutical Technology, Institute of Pharmacy,

Nirma University, Ahmedabad, Gujarat 382481, India

Full list of author information is available at the end of the article
}

(C) The Author(s) 2021. Open Access This article is licensed under a Creative Commons Attribution 4.0 International License, which permits use, sharing, adaptation, distribution and reproduction in any medium or format, as long as you give appropriate credit to the original author(s) and the source, provide a link to the Creative Commons licence, and indicate if changes were made. The images or other third party material in this article are included in the article's Creative Commons licence, unless indicated otherwise in a credit line to the material. If material is not included in the article's Creative Commons licence and your intended use is not permitted by statutory regulation or exceeds the permitted use, you will need to obtain permission directly from the copyright holder. To view a copy of this licence, visit http://creativecommons.org/licenses/by/4.0/. 


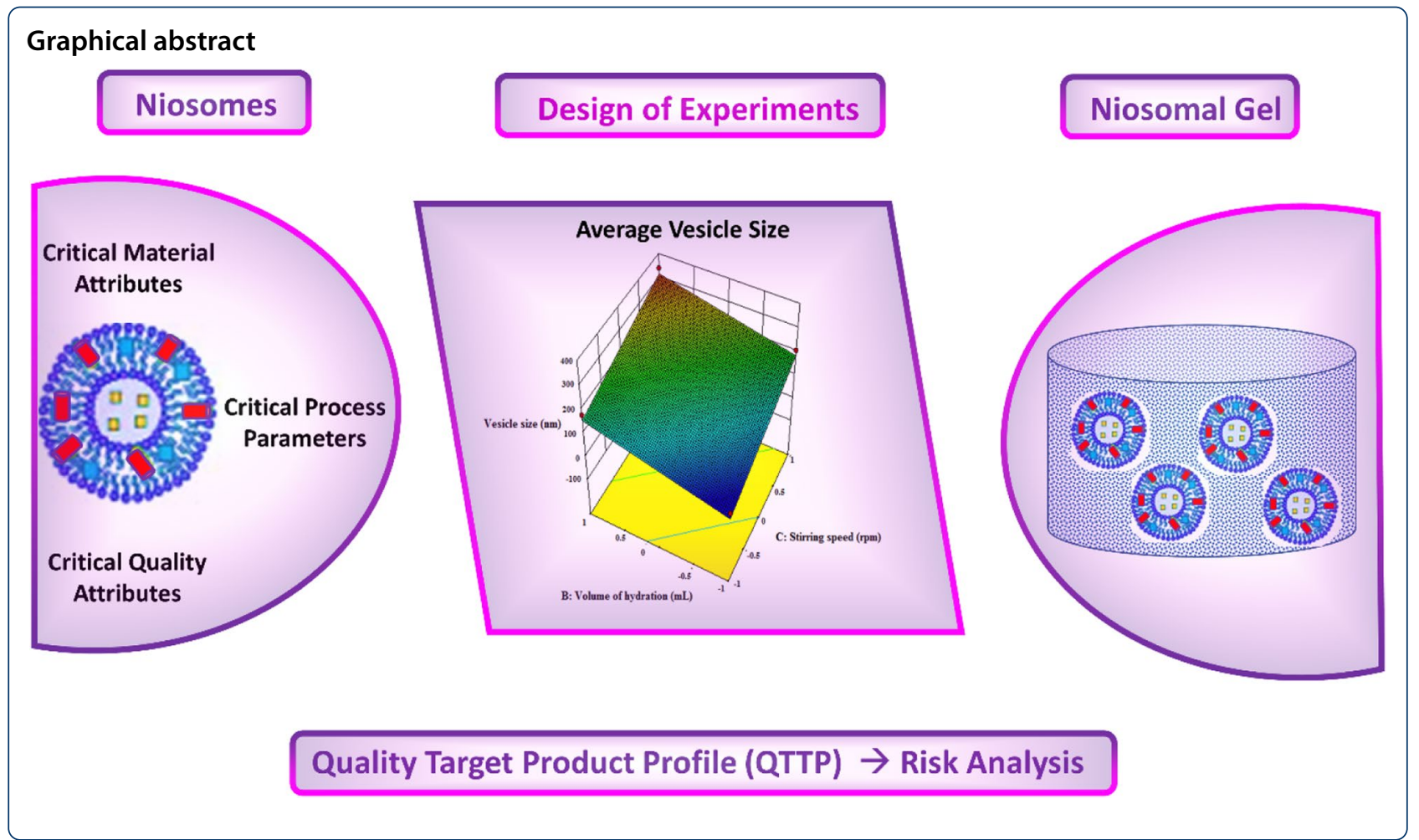

\section{Introduction}

Drug administration via transdermal route has been evolving as one of the most preferred alternative routes for drug delivery. The possible reasons include, but not limited to, ease of use, non-invasive, and improved patient compliance. In addition to this, transdermal delivery systems have clear advantages over oral drug administration as first pass metabolism is avoided; factors such as gastrointestinal $\mathrm{pH}$, effect of food, and peristaltic movement will not be applicable to reap the therapeutic benefits of a particular active pharmaceutical ingredient. Transdermal administration may serve as a best alternative to oral administration for most efficacious therapeutic effect (Chaturvedi et al. 2018; Moghassemi and Hadjizadeh 2014; Shah et al. 2014; Toyoda et al. 2015). The transdermal delivery systems have been widely used ranging from the treatment of cutaneous disorders (e.g., skin cancer) or cutaneous manifestation (e.g., psoriasis) to some general disorders due to its systemic effect. Nonetheless, the formulation scientists must be cautious about the limitation associated with transdermal delivery systems, wherein the skin barrier properties may lead to inadequate drug permeation transdermally. Moderately, lipid-soluble compounds are well accepted in the stratum corneum due to their resemblance to a homogenous lipid membrane. Thus, a relatively lipophilic drug in a lipidic drug delivery system can deal with diffusivity problem to a great extent. Currently, this concept is being intensively investigated for the skin cancer treatment (Manosroi et al. 2012; Rawal et al. 2018; Tagne et al. 2008; Zeinali et al. 2021).

Gamma oryzanol (OZ) is a naturally occurring compound, consisting of sterols and ferulic acid, obtained from rice bran oil (Liang et al. 2014; Zhao and Moghadasian 2008). The potent antioxidant is widely used as a food stabilizer (Ghaderi et al. 2014) and as an active pharmaceutical ingredient in the pharmaceutical industry (Juliano et al. 2005). The other health benefits of the antioxidant include inhibition of the platelet aggregation (Panchal et al. 2017; Reena et al. 2010), improvement in plasma lipid composition by reducing total plasma cholesterol, and increase of HDL cholesterol levels (Bhaskaragoud et al. 2016; Kozuka et al. 2013). OZ upon transdermal administration diffuses along the skin layers and forms a reservoir system in the skin followed by a controlled drug release. Small amounts of OZ may be systemically absorbed; however, its natural origin does not aggravate the side effects even after systemic absorption. One of the major challenge with OZ and other antioxidants are photostability issues upon long exposures to light and air (Kumar 2021; Lee 2016; Shah et al. 2019). To overcome this issue, vesicular systems are not only used to entrap and protect antioxidants, but also serve as a vehicle for the delivery of these antioxidants at the target 
site (Suh et al. 2007). This encapsulation enhances the stability of drug molecule as well as improves skin hydration (Lohcharoenkal et al. 2011).

Different formulations such as liposomes, nanoemulsions, lotions, chitosan nanoparticles, and nanoethosomal formulation have been employed for topical delivery (Rajput and Butani 2019). However, it is very challenging to control physicochemical stability, drug penetration, prolonged skin retention, and drug toxicity in these formulations. Vesicular systems are laminar spheroidal structures formed from the self-assembly of amphiphiles in aqueous media resulting in closed bilayer structures. They are considered as primitive cell models and cell-like bioreactors and matrices for bioencapsulation of both hydrophilic as well as hydrophobic drugs (Moghassemi and Hadjizadeh 2014; Sharma et al. 2015). Recently, non-ionic surfactants vesicles known as niosomes are explored and investigated as a potential drug delivery system and a suitable alternative to the conventional drug delivery systems (Hamishehkar et al. 2013). The non-ionic surfactants used to formulate niosomes are usually biodegradable, non-immunogenic, and biocompatible. Surfactants also act as penetration enhancers by removing mucous layer and breakdown functional complexes (Muzzalupo et al. 2011). Niosomes can provide a local depot formation in the skin while reducing percutaneous absorption, hence minimizing the risk of system side effects (Mezei and Gulasekharam 1982). In comparison to phospholipid vesicles, niosomes offer higher chemical and physical stability in a cost-effective manner and reduced toxicity due to lower non-specific tissue interaction (Nasr et al. 2008). From scientific perspective, niosomes carry definite advantage over conventional liposomes. These vesicles have shown prolonged residual time of the drugs in the dermal layers, improved drug penetration and minimal drug degradation or inactivation (Priprem et al. 2015). They are believed to improve the properties of stratum corneum by replenishing the lost skin lipids and reducing transdermal water loss (Lohcharoenkal et al. 2011). Moreover, extensive research work conducted and published suggests the vesicle formulation exhibits enhanced cutaneous drug availability against conventional dosage forms (Hamishehkar et al. 2013).

Niosomes have been extensively investigated for many pharmaceutical agents including anti-tubercular, antileishmanial, anti-inflammatory, hormonal drugs, and oral vaccines (LezamaDávila 1999; Marianecci et al. 2012; Mehta et al. 2011; Pardakhty et al. 2007). The authors strongly considered the anti-cancer properties of OZ and several discussed benefits of niosomal drug delivery systems for further investigation in the current work. The main goal of present study was to develop and characterize $\mathrm{OZ}$ niosomes as gel formulation for the skin cancer treatment. This is the second case from our laboratory that has explored the novel application of $\mathrm{OZ}$ using niosomes as carrier for topical use.

\section{Material and methods Material}

OZ was obtained from Tokyo Chemical Company (Tokyo, Japan) as a gift sample. Span 60, Carbopol 940P, triethanolamine (TEA), methyl paraben, and propyl paraben were procured from the Central Drug House Ltd (New Delhi, India). Dicetyl phosphate and cholesterol were obtained from Sigma Aldrich Ltd. (Mumbai, India). Chloroform was obtained from Merck specialties Ltd. (New Delhi, India). All the other solvents and chemicals used were of analytical grade.

\section{Niosomes preparation}

The niosomes were prepared using solvent injection method. Accurately weighed quantities of OZ, span 60, and dicetyl phosphate (DCP) were dissolved in chloroform. The solution thus obtained was injected with the help of a needle into phosphate saline buffer $\mathrm{pH} 7.4$ (PBS) preheated at $60^{\circ} \mathrm{C}$ with continuous agitation using a mechanical stirrer. The resulting solution was cooled down to $40{ }^{\circ} \mathrm{C}$ with continuous stirring. The solution was then sonicated to obtain niosomal formulation containing multi-lamellar vesicles.

\section{Niosomal gel preparation}

Carbopol 940 was dispersed in the above obtained niosomal formulation and stirred gently to obtain a homogenous solution. A mixture of methyl paraben and propyl paraben in propylene glycol (PG) was added to the above dispersion and stirred continuously to achieve homogeneity. The resulting dispersion was transformed into a gel by $\mathrm{pH}$ adjustment using TEA. TEA was added with gentle mixing until a uniform viscous gel is obtained.

\section{Optimization}

Table 2 shows the potential risk of the formulation and process variables on the critical quality attributes (CQAs). For each component that has a high and medium risk of having an impact, the CQAs are further investigated. The operating ranges for the variables were optimized in a way that they pose minimum risk to the CQAs by One Variable at a Time (OVAT) optimization and factorial design.

\section{One Variable at a Time optimization}

OVAT optimization was done for all the variables which had medium to high risk of affecting the CQAs. In OVAT analysis, only one variable was studied at a time while 
the other variables are kept constants. Every variable was studied individually to obtain a working range or value where they would have a minimum impact on the CQAs. The variables that were successfully optimized by this analysis were the amount of charge inducer (DCP), span 60 to cholesterol ratio, temperature, needle size, flow rate, and sonication. The variables that could not be optimized by OVAT and were taken ahead for optimization by full factorial design were drug to span 60 ratio, volume of hydration, and stirring speed.

\section{$2^{3}$ full factorial design}

Based on the preliminary trials, three parameters, i.e., drug to span 60 ratio $\left(X_{1}\right)$, volume of hydration $\left(X_{2}\right)$, and stirring speed $\left(X_{3}\right)$ were identified as independent formulation and process variable which have highest risk of impacting the CQAs. To optimize these variables at two levels, $2^{3}$ full factorial design was selected. The dependent variable (CQAs) taken were average vesicle size $\left(Y_{1}\right)$ and entrapment efficiency \% $\left(Y_{2}\right)$. Levels of variables in $2^{3}$ full factorial design are listed in the Table 1 . The Design Expert Software version 9.0 was used for applying. Factorial design and the polynomial equation derived are shown below:

$$
Y=\beta_{0}+\beta_{1} X_{1}+\beta_{2} X_{2}+\beta_{3} X_{3}+\beta_{12} X_{12}+\beta_{13} X_{23}+\beta_{23} X_{13}
$$

The linear equation generated after the statistical analysis exemplifies the quantitative effect of independent variables $\left(X_{1}, X_{2}, X_{3}\right)$ on the response $(Y)$. In the equation, the regression coefficient of the independent variable $\beta_{\mathrm{i}}$ $(i=1,2,3)$ reflects the relative importance of each factor whereas coefficient associated with more than one factor $\beta_{\mathrm{ij}}(i=1,2,3 ; j=1,2,3)$ reflects the interaction among the factors. The magnitude of the coefficient in the equation indicates whether a factor has synergistic (positive sign) or antagonistic effect (negative sign) on the response $Y$.

A best fit linear quadratic equation was selected based on several factors like standard deviation, correlation coefficient, predicted residual sum of squares, and by $3 \mathrm{D}$

Table 1 Levels of variables in $2^{3}$ full factorial design

\begin{tabular}{llc}
\hline Independent variables & \\
\hline Factors & \multicolumn{2}{l}{ Levels, coded (actual) } \\
\cline { 2 - 3 } & Low & High \\
\hline X1: Drug to span 60 molar ratio & $-1(1: 4)$ & $+1(1: 8)$ \\
X2: Volume of hydration (PBS 7.4) & $-1(10 \mathrm{ml})$ & $+1(100 \mathrm{ml})$ \\
X3: Stirring speed & $-1(1000 \mathrm{rpm})$ & $+1(2500 \mathrm{rpm})$ \\
Dependent variables & & \\
Y1:Average vesicle size $(\mathrm{nm})$ & & \\
Y2: Entrapment efficiency (\%) & & \\
\hline
\end{tabular}

response surface plot generated by the Design Expert software ( $p<0.05$ was considered as level of significance).

\section{Model validation}

In order to validate the equation derived after applying design of experiment (DOE), a check point batch with the predicted levels was prepared and evaluated. Thereafter, the calculated values of different responses are compared with the practical values.

\section{Characterization of niosomes Average vesicle size and polydispersity index}

The average size of maximum population of niosomal formulation was measured by dynamic light scattering using zetasizer (ZS 200, Malvern Instruments, UK). The formulation was diluted 10 times with $\mathrm{pH} 7.4$ phosphate saline buffer prior to measurement. Vesicle size measurements and PDI were carried out by placing $1 \mathrm{ml}$ of diluted formulation in a polystyrene cuvette. The size was reported as volume equivalent sphere diameter.

\section{\% Entrapment efficiency (\% EE)}

Drug entrapment efficiency was determined by solid phase extraction method using a C-18 column. Niosomes were collected as first eluent with phosphate buffer 7.4 and diluted with ethanol. Ethanol causes the niosomes to break after which the concentration of the drug can be measured at $326 \mathrm{~nm}$ using UV spectrophotometer from Shimadzu (UV 1900i, Kyoto, Japan). The second eluent obtained with ethanol contains unentrapped drug. The $\% \mathrm{EE}$ was calculated for both entrapped or unentrapped drug.

$$
\% E E=\frac{\text { Initial amount of } \mathrm{OZ}-\text { Amount of free } \mathrm{OZ}}{\text { Initial amount of } \mathrm{OZ}} * 100
$$

\section{Zeta potential}

The zeta potential of OZ loaded niosomes was computed using Malvern Zetasizer (ZS 200, Malvern, UK) at $25^{\circ} \mathrm{C}$. The measurement was carried out talking $1 \mathrm{ml}$ of the 10 times diluted formulation in disposable folded capillary cell. For accuracy, the sample analysis was carried out in triplicates and the results are expressed as the mean voltage.

\section{Transmission electron microscopy (TEM)}

The surface morphology of the hydrated vesicles was studied using transmission electron microscopy by JEOL (JEM-Z200FSC, Tokyo, Japan). A droplet of the 
dispersion was layered on a carbon film-covered copper grid (200\# mesh) and allowed to adhere on the carbon substrate for a min. The excess liquid was then removed by blotting using a filter paper. The sample was air dried and examined under TEM. diluted with ethanol and their absorbance was determined by UV Spectrometer at $326 \mathrm{~nm}$. Drug diffused and drug retained on the skin after each time point was computed.

The \% drug retained was then calculated by the following equation:

$$
\% \text { drug retained }=\% \text { of initial drug }-(\% \text { drug diffused }+\% \text { drug remaining in the donor compartment })
$$

\section{Characterization of niosomal gel pH measurement}

$\mathrm{pH}$ of the niosomal solution was measured by taking $10 \mathrm{ml}$ of the formulation in a beaker. The measurement of the $\mathrm{pH}$ was done using a calibrated digital pH meter by Elico (LI127, Telangana, India) at room temperature.

\section{Viscosity}

The viscosity of gel was determined using viscometer by Brookfield Engineering Laboratories Inc. (Brookfield, DV-II, MA, USA). The viscosity was measured using spindle number 18 at $0.3 \mathrm{rpm}$ and $25^{\circ} \mathrm{C}$ temperature.

\section{Draize test (skin irritation test)}

Albino rabbits were used for the Draize test to check the skin irritation. It is an acute toxicity test which rivets studying the skin irritability of the formulation on rabbits. The procedure involves applying of $0.5 \mathrm{ml}$ of niosomal gel on skin (previously shaved and washed) of conscious rabbit and observing the effects after 14days. Any signs of any erythema, edema, or redness were seen and recorded.

\section{Ex vivo permeation studies to evaluate drug retention in formulation}

The ex vivo permeation of OZ from OZ-loaded niosomal gel was studied using skin of freshly scarified rat using Franz diffusion cell by Orchid Scientifics (EMFDC - 06, Maharashtra, India) placed in a diffusion cell assembly. The diffusion media used was freshly prepared pH7.4 PBS which was filled in the receptor compartment $(20 \mathrm{ml})$. A rat skin was placed between the receptor and donor compartment in a way that there is no air bubble formation in the cell. The temperature was maintained at $32 \pm 0.5{ }^{\circ} \mathrm{C}$ to mimic the skin temperature. The stirring speed used for permeation study performed using at $100 \mathrm{rpm}$. Aliquots of $2 \mathrm{ml}$ were withdrawn at regular time intervals and replaced by an equal volume of fresh diffusion media to maintain sink condition. The aliquots were suitably

\section{Stability studies}

The stability studies were performed on the final optimized batch as per ICH regulatory guidelines (Guideline 2003). All the batches of niosomal gel were stored in wide mouthed glass container at $25^{\circ} \pm 2{ }^{\circ} \mathrm{C} / 60 \% \pm 5 \% \mathrm{RH}$ for the period of 3 and 6 months. The samples were then analyzed for their rheological properties and diffusion profile.

\section{Statistical analysis}

Each batch was prepared three times, and data values were expressed as mean \pm standard deviation. A difference between means was considered significant $(P \leq 0.005)$.

\section{Result and discussion}

\section{QbD approach for formulation development}

In recent times, $\mathrm{QbD}$ has become a new reliable approach for obtaining a robust drug product. QTTP preparation of the final product is the first step. Research efforts are well received, if the quality goal for the speculated drug product is clear right from the conception of the research idea. This approach ensures the in-process quality of the product as compared to quality check of the final drug product. The CQAs are the drug product characteristics, shortlisted from QTTPs, which highlights important quality attributes to be monitored during the pharmaceutical unit operations to achieve the desired drug product quality. Critical material attributes (CMAs) and critical process parameters (CPPs) are variables that impact the CQAs and require optimization to attain a product with target qualities. Critical CMAs and CPPs are identified by risk assessment. DoE is a widely used tool for screening of the critical CMAs and CPPs. The graphs obtained from the response surface DoE can be employed for generating design space for the CMAs and CPPs. Finally, a control strategy is designed to ensure that the optimized manufacturing process within the operating values consistently produce a highest quality drug product. The QbD application leads to continual improvement in revising optimized operating range, models, and design space, if any 
quality changes are required in the formulation components as well as process parameters.

\section{Quality Target Product Profile (QTPP) and Critical Quality Attributes (CQAs)}

QTPP is an essential element of the formulation development using QbD approach and forms the basis for the selection of the CQAs for a product. QTPP is the prospective summary of those features of the drug product that needs to be achieved in order to obtain the desired product quality and safety attributes. QTPP elements of niosomal solution and their target with justification are described in Table 2 (Al Sabaa et al. 2018).

\section{$Q b D$ in transdermal niosomal formulation}

The QbD application using risk assessment and control strategy is well recognized in the pharmaceutical industry to discover the potential failure modes for risk mitigation during the formulation development. In the present work, the overall risk assessment was performed using risk ranking, whereas risk control and risk review were investigated as a part of QbD (Shah et al. 2020).

\section{One Variable at a Time (OVAT)}

The OVAT analyses led to successful optimization of operating value/range for variables such as the amount of charge inducer (DCP), span 60 to cholesterol ratio, temperature, needle size, flow rate, and sonication. The optimized values/ranges are mentioned in Table 3. Further optimization of the selected factors (drug to span 60 ratio, volume of hydration, and stirring speed) was applied by employing full factorial design; these working values were kept constant in the experimental runs.

\section{$2^{3}$ factorial design}

DoE was implemented to obtain an optimized batch with minimum possible trials. There are several designs which could be applied depending on the factors and levels of the study. Out of various DoE approaches, a $2^{3}$ full factorial design was carefully chosen to study the influence of the selected operational parameters on the final formulation. Hence, the resulting experimental design comprised of 8 runs with three optional central batches. The authors decided to include all three central batches for building confidence in the optimization. A total of 11 runs were executed as described in Table 4. A series of experimental trials were performed and evaluated based on the setup of experimental runs taken at different combinations of factor levels. All the values of responses were fitted to a linear equation model, and the adequacy of this model was checked by various statistical parameters such as ANOVA, lack of fit, and multiple correlation coefficients $R^{2}$ tests.

\section{Average vesicle size}

Nanovesicles with a vesicle size of $300 \mathrm{~nm}$ or less are anticipated to deliver drug to minimal extent deep into the dermal layers. The maximum drug deposition is expected from vesicle size of $70 \mathrm{~nm}$ or below in both epidermal and dermal layers (Hua 2015; Verma et al. 2003). Nanoparticles with a vesicle size of $6-7 \mathrm{~nm}$ may be absorbed via the lipidic channels, whereas the aqueous pores facilitate a particle size of less than $36 \mathrm{~nm}$. In

Table 2 Quality Target Product Profile (QTPP) for niosomal formulation

\begin{tabular}{|c|c|c|}
\hline QTPP elements & Target & Justification \\
\hline Dosage form & Colloidal carrier drug delivery system & $\begin{array}{l}\text { For targeted drug delivery with longer residence time in } \\
\text { skin and relatively less systemic absorption }\end{array}$ \\
\hline Dosage design & Niosomes & $\begin{array}{l}\text { To provide a lipidic environment to the drug and to obtain } \\
\text { a higher retention in the skin. Niosomes offer higher } \\
\text { entrapment, better stability, and are less prone to leakage } \\
\text { as compared to liposomes }\end{array}$ \\
\hline Route of administration & Topical & $\begin{array}{l}\text { For non-invasive drug delivery with minimal systemic } \\
\text { absorption }\end{array}$ \\
\hline Stability & $\begin{array}{l}\text { Short term stability study at room temperature }\left(25^{\circ} \mathrm{C} \text {, }\right. \\
60 \% \mathrm{RH}) \text { and refrigerated condition }\left(4-8{ }^{\circ} \mathrm{C}\right) \text { for } 6 \\
\text { months }\end{array}$ & The product should have enough shelf life \\
\hline \multirow[t]{3}{*}{ Dosage product quality attribute } & Physical attributes ${ }^{a}$ & Required for product efficacy and patient acceptability \\
\hline & \% Entrapment efficiency & $\begin{array}{l}\text { The higher the encapsulation efficiency, the better the } \\
\text { yield during development and formulation is economic }\end{array}$ \\
\hline & Vesicle size and polydispersity index & $\begin{array}{l}\text { Optimum vesicle size to efficiently penetrate the skin } \\
\text { but also provide maximum skin retention and minimum } \\
\text { systemic absorption. The smaller the PDI, the better uni- } \\
\text { formity and higher stability }\end{array}$ \\
\hline
\end{tabular}

\footnotetext{
${ }^{a}$ Physical attributes include the following: appearance, $\mathrm{pH}$, odor, and rheological attributes (viscosity, spreadability)
} 
Table 3 Range of optimized variables

\begin{tabular}{|c|c|c|}
\hline Variable & $\begin{array}{l}\text { Optimized } \\
\text { operating value/ } \\
\text { range }\end{array}$ & Justification \\
\hline \multicolumn{3}{|l|}{ Formulation variables } \\
\hline Amount of charge inducer (DCP) & $8-16 \mathrm{mg}$ & $\begin{array}{l}\text { It was observed that as the concentration of DCP increased, the aggregation reduced. This may } \\
\text { be because of the repulsive force developed by negative chargeon niosomes induced by DCP. } \\
\text { The results of zeta potential showed that at the concentration of } 8 \mathrm{mg} \text { and above it attains } \\
-30 \mathrm{mV} \text { charge which satisfies the criteria for stable formulation with no agglomeration. There- } \\
\text { fore, further formulation optimization was carried out by keep DCP concentration between } 8 \mathrm{mg} \\
\text { and } 16 \mathrm{mg}(36.9 \mathrm{mV}) \text {. Also, the vesicle size decreased comparatively, because of repulsion, which } \\
\text { inhibited formation of aggregates }\end{array}$ \\
\hline Span 60 to cholesterol ratio & $2: 2-3: 1$ & $\begin{array}{l}\text { It was observed that as the span } 60 \text { to cholesterol ratio was increased, the aggregation reduced. } \\
\text { This might be due to the increase in the amount of surfactant }\end{array}$ \\
\hline \multicolumn{3}{|l|}{ Process variables } \\
\hline Temperature & $63^{\circ} \mathrm{C} \pm 3{ }^{\circ} \mathrm{C}$ & $\begin{array}{l}\text { The phase transition temperature of span } 60 \text { is } 55^{\circ} \mathrm{C} \text {, and trials showed lump formation at a tem- } \\
\text { perature below } 60^{\circ} \mathrm{C} \text {. A temperature above } 70{ }^{\circ} \mathrm{C} \text { can cause degradation of the drug. Therefore, } \\
\text { the temperature should preferably be maintained in between } 60 \text { and } 66^{\circ} \mathrm{C}\end{array}$ \\
\hline Needle size & 24 gauge & $\begin{array}{l}\text { Initial attempts depicted that there was some effect of higher gauge size needle on vesicle size } \\
\text { and polydispersity index. For further optimization, 24-gauge needle was used due to smaller } \\
\text { vesicle size and lower PDI when compared with other two sizes ( } 18 \text { and } 22 \text { gauge) }\end{array}$ \\
\hline Flow rate & $2 \mathrm{ml} / \mathrm{min}$ & $\begin{array}{l}\text { The average vesicle size and PDI showed a non-linear response with flow rate of injection, i.e., } \\
\text { change in flow rate does not affect vesicle size and PDI significantly. Hence, for reducing the } \\
\text { time for the formulation process, a higher flow rate of } 2 \mathrm{ml} / \mathrm{min} \text { can be used }\end{array}$ \\
\hline Sonication & $5 \mathrm{~min}$ & $\begin{array}{l}\text { With increase in the sonication time, decrease in entrapment efficiency and average vesicle size } \\
\text { was observed. This was might be due to rupture of niosomes upon sonication for longer dura- } \\
\text { tion. Therefore, it was necessary to keep the sonication time constant at } 5 \text { min }\end{array}$ \\
\hline
\end{tabular}

general, particles or vesicles in the $10-210 \mathrm{~nm}$ size range may favorably pass through the transfollicular route (Geusens et al. 2011; Zeb et al. 2016).

Equation in terms of coded factors for average vesicle size:

Table 4 Design matrix and response for $2^{3}$ factorial design batches $\left[X_{1}\right.$-drug to span 60 molar ratio, $X_{2}$-volume of hydration (PBS 7.4), $X_{3}$-stirring speed, $Y_{1}$-average vesicle size $(\mathrm{nm})$, and $Y_{2}$-entrapment efficient (\%)]

\begin{tabular}{llllll}
\hline Batch no. & \multicolumn{5}{c}{ Independent variables in coded form } \\
\cline { 2 - 7 } & $\boldsymbol{X}_{\mathbf{1}}$ & $\boldsymbol{X}_{\mathbf{2}}$ & $\boldsymbol{X}_{\mathbf{3}}$ & $\boldsymbol{Y}_{\mathbf{1}}$ & $\boldsymbol{Y}_{\mathbf{2}}$ \\
\hline B1 & -1 & -1 & -1 & $240.0 \pm 1.1$ & $60.5 \pm 1.1$ \\
B2 & +1 & -1 & -1 & $208.6 \pm 0.9$ & $59.1 \pm 3.1$ \\
B3 & -1 & +1 & -1 & $315.0 \pm 2.1$ & $61.4 \pm 0.9$ \\
B4 & +1 & +1 & -1 & $340.7 \pm 2.9$ & $64.9 \pm 0.3$ \\
B5 & -1 & -1 & +1 & $65.1 \pm 0.6$ & $55.3 \pm 0.5$ \\
B6 & +1 & -1 & +1 & $45.0 \pm 0.6$ & $48.3 \pm 0.8$ \\
B7 & -1 & +1 & +1 & $150.6 \pm 1.5$ & $84.6 \pm 1.9$ \\
B8 & +1 & +1 & +1 & $179.4 \pm 1.9$ & $88.5 \pm 1.6$ \\
B9 & 0 & 0 & 0 & $105.8 \pm 1.2$ & $70.8 \pm 2.5$ \\
B10 & 0 & 0 & 0 & $115.5 \pm 1.1$ & $72.1 \pm 1.7$ \\
B11 & 0 & 0 & 0 & $110.0 \pm 0.8$ & $70.9 \pm 1.4$ \\
B12 (checkpoint batch) & -0.5 & -0.5 & -0.5 & $190.7 \pm 1.1$ & $65.6 \pm 1.8$ \\
B13 (optimized batch) & -0.5 & +1 & +1 & $196.6 \pm 0.9$ & $78.31 \pm 1.4$ \\
\hline
\end{tabular}

$$
\begin{aligned}
Y_{1}= & +170.45+0.25 \times X_{1}+53.25 \times X_{2}-83 \\
& \times X_{3}+13.25 \times X_{1} X_{2}+2 \times X_{1} X_{3}+1.5 X_{2} X_{3}
\end{aligned}
$$

The linear equation (4) generated after the statistical analysis exemplifies the quantitative effect of independent variables $X_{1}, X_{2}$, and $X_{3}$ on the response $Y_{1}$, i.e., average vesicle size. The correlation coefficient $R^{2}$ value was found to be 0.8443 indicated good fit of the linear equation. From the results of ANOVA, $p$ value was found to be less than 0.05 indicated that all the three factors have a significant effect on the response $Y_{1}$. The response surface plot shown in Fig. 1a was drawn using design expert software version 9.0 on the basis of equation generated to estimate and understand the effect of the independent variables on the average vesicle size in a graphical way.

From the linear Equation (4) and response surface plots, it can be concluded that the factors $X_{1}$ and $X_{2}$ showed positive effect while factor $X_{3}$ had negative effect on average vesicle size. The major negative effect of factor $X_{3}$ (stirring speed) on average vesicle size could be due to shear force which increases with increase in stirring speed and hence reduces the vesicle size. The little positive effect of factor $X_{1}$ (drug to span 60 ratio) which could be due to higher concentration of span 60 which remains in the solution and forms aggregates which lead to an increase in the vesicle size. The major positive 


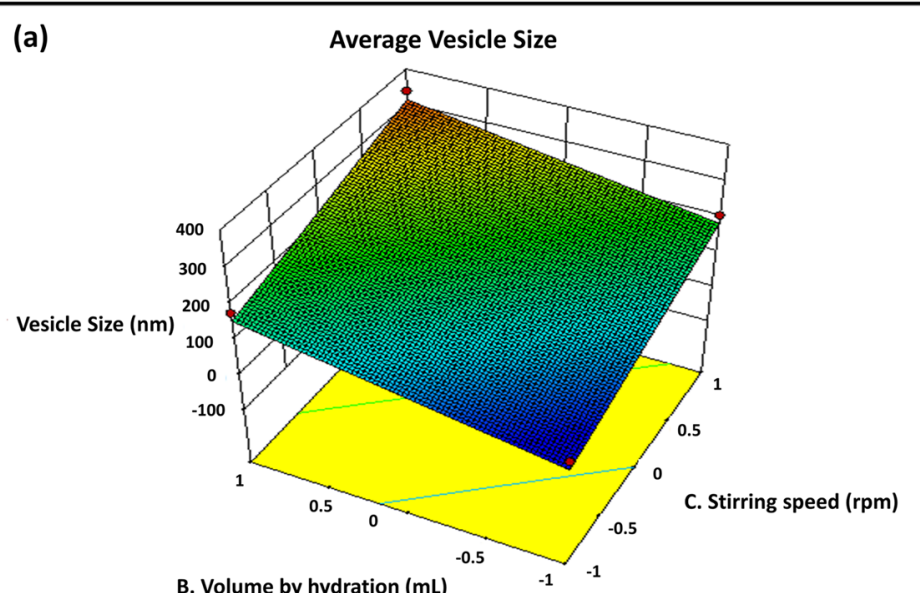

(b)

B. Volume by hydration $(\mathrm{mL})$
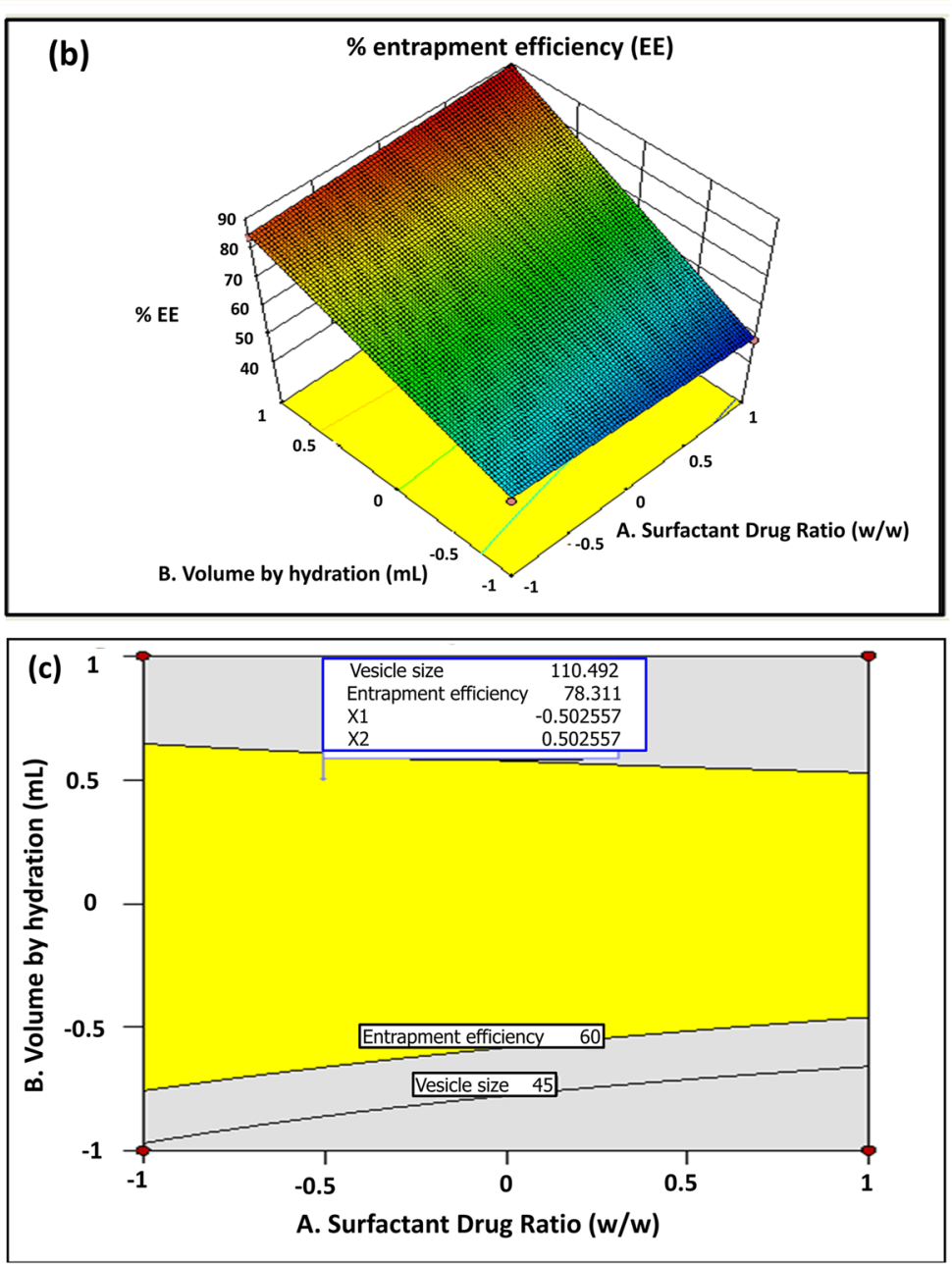

Fig. 1 a Response surface plots for average vesicle size, b response surface plots for \% entrapment efficiency, and c overlay plot showing design space 
effect of factor $X_{2}$ (volume of hydration) could be due to higher amount of buffer available for vesicle arrangement, where the aqueous media may have entrapped inside the vesicle resulting in an increased vesicle size. Value of coefficient of interaction between the factor $X_{2}$ and $X_{3}$ has shown its remarkable effect on average vesicle size.

\section{$\%$ Entrapment efficiency equation in terms of coded factors for \% entrapment efficiency}

The entrapment efficiency characterization for any vesicle-based formulation is imperative to determine its successful administration. Entrapment efficiency enabled the present research scientists to determine the amount of $\mathrm{OZ}$ entrapped within the niosomes. The below polynomial equation was obtained for the entrapment efficiency of OZ:

$$
\begin{aligned}
Y_{2}= & +67.27-1.25 \times X_{1}+8.25 \times X_{2}+2.75 \\
& \times X_{3}+3 \times X_{1} X_{2}+0.5 \times X_{1} X_{3}+9 X_{2} X_{3}
\end{aligned}
$$

The linear equation (5) generated after the statistical analysis exemplifies the quantitative effect of independent variables $X_{1}, X_{2}$, and $X_{3}$ on the response $Y_{2}, \%$ drug entrapment efficiency. The correlation coefficient $R^{2}$ value was found to be 0.9653 indicated good fit of the linear equation and $p$ value $<0.05$ indicated significant effect of all three factors. Factor $X_{2}$ and $X_{3}$ showed positive effect while factor $X_{1}$ showed negative effect on entrapment efficiency. Higher value of coefficient of factor $X_{2}$ has shown that it has the maximum effect on the \% drug entrapment efficiency among all other factors. The response surface plot has been shown in Fig. 1b. The plot clearly shows that drug to span 60 ratio has most significant effect on \% drug entrapment efficiency as compared to volume of hydration.

Drug entrapment efficiency can also be correlated with vesicle size. Due to the significant increase in vesicle size, entrapment efficiency increased. The increase in \% drug EE with increase in the concentration of span 60 might be due to high number of non-polar chains in span 60 which might have entrapped more amount of drug in the vesicular bi-layers. Factor $X_{3}$ (stirring speed) was kept constant at high level in order to achieve the \% drug entrapment efficiency with highest desirability. Values of coefficient of interaction between the factors also have some effect on the response but were found to be non-significant.

Yellow region/design space in the overlay plot (Fig. 1c) shows the acceptable region, wherein the preparation of any batch within this space will lead to a product possessing the criteria set for optimization, i.e., vesicle size less than $200 \mathrm{~nm}$ and \% EE more than $50 \%$.
The plot also suggests that the volume of hydration is a critical parameter. The value of volume of hydration if chosen anywhere between -0.5 and +0.5 will produce a product with the desired characteristics within the optimized range. The plot depicts that the value of "drug to span 60 ratio" is a less critical factor and can be chosen conveniently between -1 and +1 as desired by the formulator.

\section{Model validation}

Based on the results from factorial design experiments, it was decided to prepare a checkpoint batch using -0.5 as a level for each of the independent variables used to optimize formulation and process variables. Average vesicle size and \% entrapment efficiency of the check point batch was characterized to $190 \mathrm{~nm}$ and $65.58 \%$, respectively (Table 5 ). The observed values were similar to the values predicted from the linear polynomial equation, $184 \mathrm{~nm}$ average vesicle size, and $66.20 \%$ entrapment efficiency. Therefore, the design and statistical model incorporated in the present study are mathematically valid. The authors were able to reach to complete optimization in shortest time with minimum efforts due to organized formulation approach.

\section{Risk assessment}

On the basis of literature review, an initial risk assessment was performed to identify CMAs and CPPs whose change may influence potential CQAs, namely, vesicle size, \% EE, and zeta potential. Variables affecting the CQAs of niosomal formulation are categorized using risk analysis which aids in identification of the failure modes of the formulation. A relative risk assessment was also performed for each variable and was ranked as high, medium, or low based on their potential risk to affect the CQAs. Those attributes that could have a high impact on the formulation CQAs required further investigation while those attributes that had low impact on the formulation CQAs required no further investigation. The initial risk analysis is shown in Table 5.

Risk management plays a most important role in new drug applications as it can assess the risk level of a drug product (i.e., formulation challenges, process issues, and/ or harmful outcomes in patients). In addition to this, risk management strategies allow the availability of highest quality drug product and increased manufacturing due to improved efficiency and smooth knowledge transfer. Risk management also provides rationale for time-efficient and cost-effect process development. Risk management is highly beneficial throughout the drug product cycle to improve processes at commercial scale (i.e., process validation). Risk assessment tools often recognizes 
Table 5 Initial and updated risk assessment of the formulation

\begin{tabular}{|c|c|c|c|c|c|c|c|c|c|}
\hline \multirow[b]{2}{*}{ CQAs } & \multicolumn{3}{|c|}{ Formulation Variables } & \multicolumn{6}{|c|}{ Process Variables } \\
\hline & $\begin{array}{l}\text { Span-60: } \\
\text { Cholester } \\
\text { ol ratio }\end{array}$ & $\begin{array}{l}\text { Charg } \\
\text { e } \\
\text { Induce } \\
\text { r } \\
\text { (DCP) }\end{array}$ & $\begin{array}{l}\text { Drug: } \\
\text { span- } \\
60 \\
\text { ratio }\end{array}$ & $\begin{array}{l}\text { Temperatur } \\
\text { e }\end{array}$ & $\begin{array}{l}\text { Flow } \\
\text { rate }\end{array}$ & $\begin{array}{l}\text { Needle } \\
\text { size }\end{array}$ & $\begin{array}{l}\text { Sonicat } \\
\text {-ion }\end{array}$ & $\begin{array}{l}\text { Volume } \\
\text { of } \\
\text { hydratio } \\
\text { n }\end{array}$ & $\begin{array}{l}\text { Stirrin } \\
\text { g } \\
\text { speed }\end{array}$ \\
\hline & \multicolumn{9}{|c|}{ Initial risk assessment before formulation development and optimization } \\
\hline $\begin{array}{l}\text { Vesicle } \\
\text { Size }\end{array}$ & High & $\begin{array}{l}\text { Mediu } \\
\mathrm{m}\end{array}$ & $\begin{array}{l}\text { Mediu } \\
\text { m }\end{array}$ & High & $\begin{array}{l}\text { Mediu } \\
\mathrm{m}\end{array}$ & $\begin{array}{l}\text { Mediu } \\
\mathrm{m}\end{array}$ & High & High & High \\
\hline$\% \mathbf{E E}$ & High & Low & High & Low & Low & Low & High & Medium & High \\
\hline \multirow[t]{2}{*}{$\begin{array}{l}\text { Zeta } \\
\text { potential }\end{array}$} & Low & High & Low & low & Low & Low & Low & Low & Low \\
\hline & \multicolumn{9}{|c|}{ Updated Risk Assessment after formulation development and optimization } \\
\hline $\begin{array}{l}\text { Vesicle } \\
\text { Size }\end{array}$ & *Low & *Low & *Low & *Low & *Low & *Low & *Low & *Low & *Low \\
\hline$\% \mathbf{E E}$ & Low* & Low & *Low & Low & Low & Low & *Low & *Low & ${ }^{*}$ Low \\
\hline $\begin{array}{l}\text { Zeta } \\
\text { potential }\end{array}$ & Low & Low* & Low & Low & Low & Low & Low & Low & Low \\
\hline
\end{tabular}

The factors with *Low category have been converted to low risk from high or medium risk

the purpose for the validation of processes (such as the include ICH Q9, quality risk management and FDA Code of Federal Regulations, CFR 21, Part 820, Quality Management Regulations) (Code U, Law P. Code of Federal Regulations (CFR) 2017; Elder and Teasdale 2017). With the detailed understanding of risk management, it was imperative to study the risk assessment and control strategies for this niosomal formulation. The risk assessment for the optimized niosomal formulation has been reported in Table 5, and the control strategies of same are shown in Table 6.

\section{Preparation and characterization of optimized batch} Preparation of optimized batch

Polynomial equations derived from factorial design experiments and risk assessment suggests drug to span 60 molar ratio was selected as 1:5 (level -0.5), volume of hydration (PBS 7.4) as $75 \mathrm{~mL}$ (level +1.0 ), and stirring speed as $2500 \mathrm{rpm}$ (level +1.0 ) showed best possible predicted average vesicle size as $110 \mathrm{~nm}$ and \% entrapment efficiency as $78 \%$. Therefore, these parameters were further selected as optimization formulation and process parameters to produce an optimized batch. The optimized batch

Table 6 Control strategies for the niosomal formulation

\begin{tabular}{|c|c|c|c|c|}
\hline Parameters & Attribute & Range studied & Optimized range & Purpose of control \\
\hline Drug to span 60 & Ratio & $1: 4-1: 8$ (molar ratio) & 1:4-1:8 (molar ratio) & To ensure higher \% drug entrapment efficiency \\
\hline PBS 7.4 & Volume & $10-100 \mathrm{ml}$ & $25-75 \mathrm{ml}$ & $\begin{array}{l}\text { To obtain a vesicle size }<200 \mathrm{~nm} \text { and higher \% drug entrapment } \\
\text { efficiency }\end{array}$ \\
\hline Stirrer & Stirring speed & 1000-2500 rpm & 1750-2500 rpm & To ensure vesicle size $<200 \mathrm{~nm}$ \\
\hline $\begin{array}{l}\text { Amount of } \\
\text { charge inducer } \\
\text { (DCP) }\end{array}$ & Zeta potential & $8 \mathrm{mg}, 16 \mathrm{mg}, 24 \mathrm{mg}$ & $8-16 \mathrm{mg}$ & $\begin{array}{l}\text { To maintain the zeta potential below }-30 \mathrm{mV} \text { so as to prevent } \\
\text { aggregation }\end{array}$ \\
\hline Heating & Temperature & $50^{\circ} \mathrm{C}-70^{\circ} \mathrm{C}$ & $62{ }^{\circ} \mathrm{C} \pm 3{ }^{\circ} \mathrm{C}$ & To prevent lump formation and also avoid degradation of drug \\
\hline Needle & Size & $18,22,24$ gauge & 24 gauge & To get optimum vesicle size \\
\hline Flow rate & Flow & $0.5,1.0,1.5,2.0 \mathrm{~mL} / \mathrm{min}$ & $2 \mathrm{~mL} / \mathrm{min}$ & $\begin{array}{l}\text { As flow rate was not impacting the product performance, higher rate } \\
\text { was selected to reduce manufacturing time }\end{array}$ \\
\hline Sonication & Time & $5 \mathrm{~min}, 15 \mathrm{~min}$ & $5 \mathrm{~min}$ & To prevent lipid degradation due to heat generation \\
\hline
\end{tabular}


was further evaluated using average vesicle size, polydispersity index, zeta potential, and transmission electron microscopy.

\section{Characterization of optimized batch of niosomes}

and niosomal gel

\section{Average vesicle size}

The optimized batch showed a vesicle size of $196.6 \pm 0.9 \mathrm{~nm}$. The vesicle size of the optimized batch as suggested by the Design Expert 9.0 software has been shown in Fig. 2a. The observed vesicle size was different as compared to the predicted vesicle size; however, as discussed earlier, nanovesicles with size $300 \mathrm{~nm}$ or less are unlikely to get absorbed into the dermal layers (Hua 2015; Verma et al. 2003). In addition to this, particles or vesicles ranging between $10 \mathrm{~nm}$ and $210 \mathrm{~nm}$ size are likely to get absorbed through the transfollicular route (Geusens et al. 2011; Zeb et al. 2016). Therefore, OZ niosomes
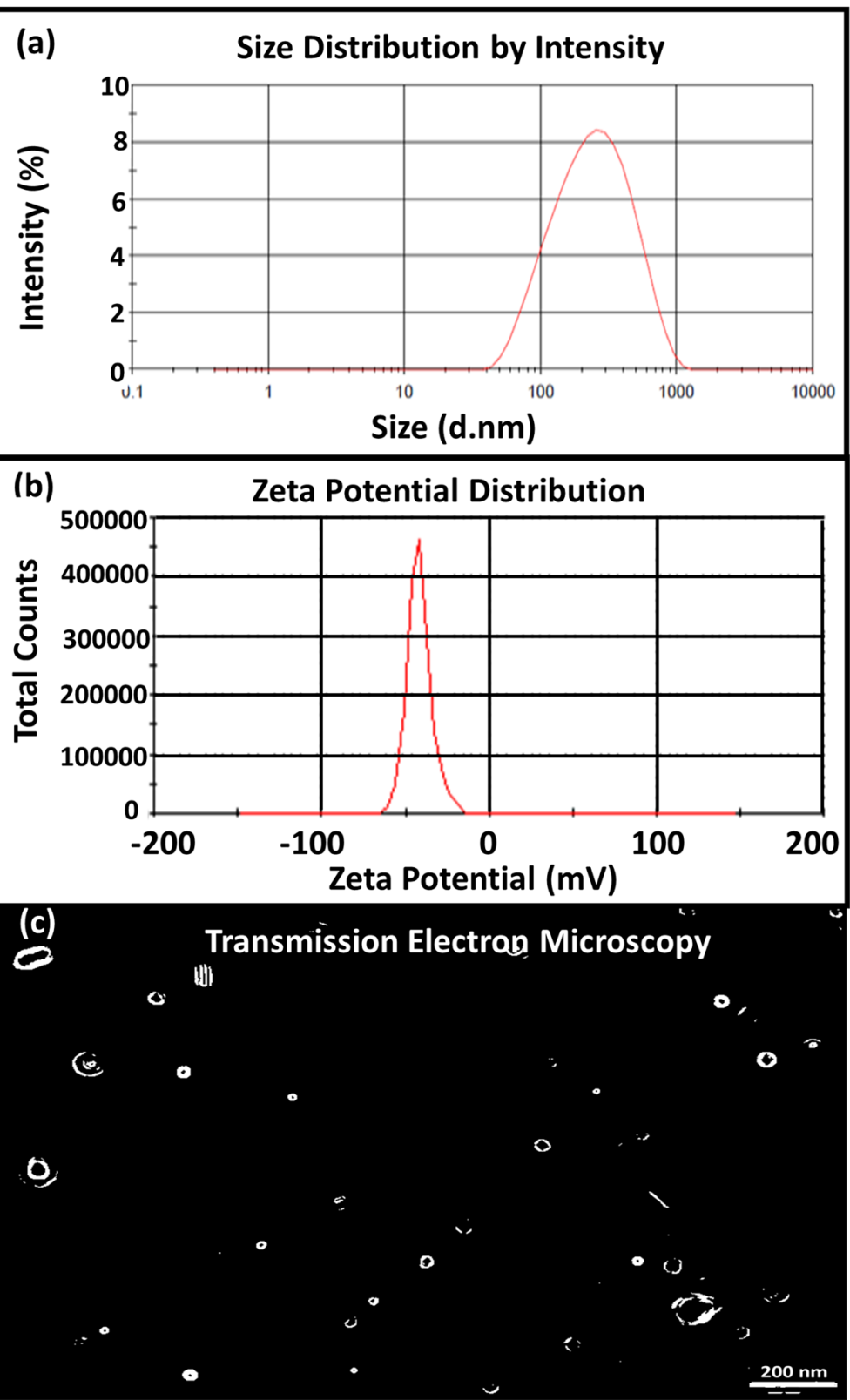

Fig. 2 a Vesicle size of the optimized batch, $\mathbf{b}$ zeta potential of the optimized batch, and $\mathbf{c}$ transmission electron microscopy (TEM) image of the optimized batch 
due to its size are expected to pass the transfollicular route and into the dermal layers up to certain extent.

\section{Polydispersity index}

The polydispersity index (PDI) values represent the average uniformity of a particle or vesicle in a solution. Large PDI values represent the large size distribution of the particles (Danaei et al. 2018). The PDI value of optimized batch was determined to be $0.268 \pm 0.02$, an important determinant of uniform particle size distribution as well as the stability of the niosomes.

\section{Zeta potential}

The zeta potential values are also indicator of the stable formulation. The values between $-30 \mathrm{mV}$ and $+30 \mathrm{mV}$ suggests the instability in the formulation (Lowry et al. 2016). The zeta potential of the optimized batch was -41.6 which was below $-30 \mathrm{mV}$, thus confirming the niosomal formulation to be stable (Fig. 2b).

\section{Transmission electron microscopy}

TEM image (Fig. 2c) revealed the morphology of niosomes to be spherical shape by TEM analysis. This further suggests that the potential absence of any irregular shaped OZ particles loaded in the niosomal formulation.

The optimized batch of niosomes was further formulated into niosomal gel using the procedure detailed in methods section. The niosomal gel was further characterized using different characterization techniques, ex vivo permeation studies, and stability studies.

\section{Characterization ( $\mathrm{pH}$ measurement, viscosity and Draize test) of OZ niosomal gel}

The $\mathrm{pH}$ of the niosomal gel was determined to be $7.3 \pm 0.1$, which can be considered within neutral range. The neutral $\mathrm{pH}$ value indicates that the niosomal gel of $\mathrm{OZ}$ can avoid any possible skin irritation rendering the niosomal formulation to be safe. Furthermore, $\mathrm{pH}$ optimization can also improve the stabilization of active pharmaceutical ingredients in gel formulation for topical use (Das and Wong 2020). The torque obtained was more than $85 \%$. This indicates that the gel formulation has an easy spreadability as well as desired skin adherence. Draize test, alternatively referred to as skin irritancy test, was carried out in rabbits. The starting point of this test was redness on the rabbit's skin (Osborne and Perkins 1994). The formulation was tested for signs of any erythema, edema, or redness. No such signs were observed suggesting the niosomal formulation was well tolerated in all rabbits (Fig. 3).

\section{Ex vivo permeation studies using $\mathrm{OZ}$ niosomal gel}

In order to assess the diffusion of $\mathrm{OZ}$ through the skin from the gel formulation, ex vivo studies using rabbit skin and Franz diffusion cells were carried out, since OZ is a water insoluble drug, and several carrier formulations have been developed to improve its penetration and localization into the deeper layers of skin tissues: with reduction in the amount of drug reaching the systemic circulation (Rodsuwan et al. 2021). Vesicular systems such as niosomes can act as a reservoir of $\mathrm{OZ}$ in the skin and could potentially enhance its permeation. The permeation of $\mathrm{OZ}$ from $\mathrm{OZ}$ niosomal gel was characterized by using OZ gel as a control. The initial \% drug content, \% drug diffused, and the calculated \% drug retained are presented in Table 7 and Fig. 4. It was observed that both $\mathrm{OZ}$ gel and $\mathrm{OZ}$ niosomal gel showed a delayed diffusion by $10 \mathrm{~min}$, but at $120 \mathrm{~min}$ time point, $\mathrm{OZ}$ niosomal gel showed fourfold increase diffusion as compared to OZ gel. Furthermore, OZ gel showed $75.21 \%$ drug in donor compartment and only $13.60 \%$ retained in the skin after $120 \mathrm{~min}$, whereas OZ niosomal gel had only $3.20 \%$ drug in donor compartment and $71.17 \%$ drug retained in the skin. These results suggest OZ gel showed less \% drug diffusion at 120 min despite majority of drug available in donor compartment followed by less \% drug retention in skin. OZ niosomal gel showed more promising results. Not only did it show higher \% drug diffusion at 120 min time point, but also it showed minimal drug in donor compartment and remaining drug in the dermal layer which is suggestive of better drug retention in skin. Improved drug retention on skin from OZ niosomal gel formulation is even more beneficial given its prophylactic use in prevention of skin cancer against UV radiation.

\section{Stability studies of OZ niosomal gel}

The final batch of niosomal gel formulation was characterized after 3 months storage at $25^{\circ} \mathrm{C} / 60 \% \mathrm{RH}$ longterm stability condition. The stability samples were analyzed for its rheological properties which showed no change. There was no significant change in the diffusion profile in the optimized batch. So, it can be concluded that the OZ niosomal gel do not show leaching of drug are stable at room temperature, and there was no leaching of drug from niosomes in its closed container (Shah et al. 2021). The stability results are reported in Table 8.

\section{Conclusion}

$\mathrm{OZ}$ is a potent anti-cancer agent which is not used widely due to poor aqueous solubility and limited permeability. In order to improve its penetration into the skin, we have designed niosomal formulation of $\mathrm{OZ}$ with a goal of enhancing its retention onto the skin for the effective skin cancer treatment. The developed vesicles were spherical 


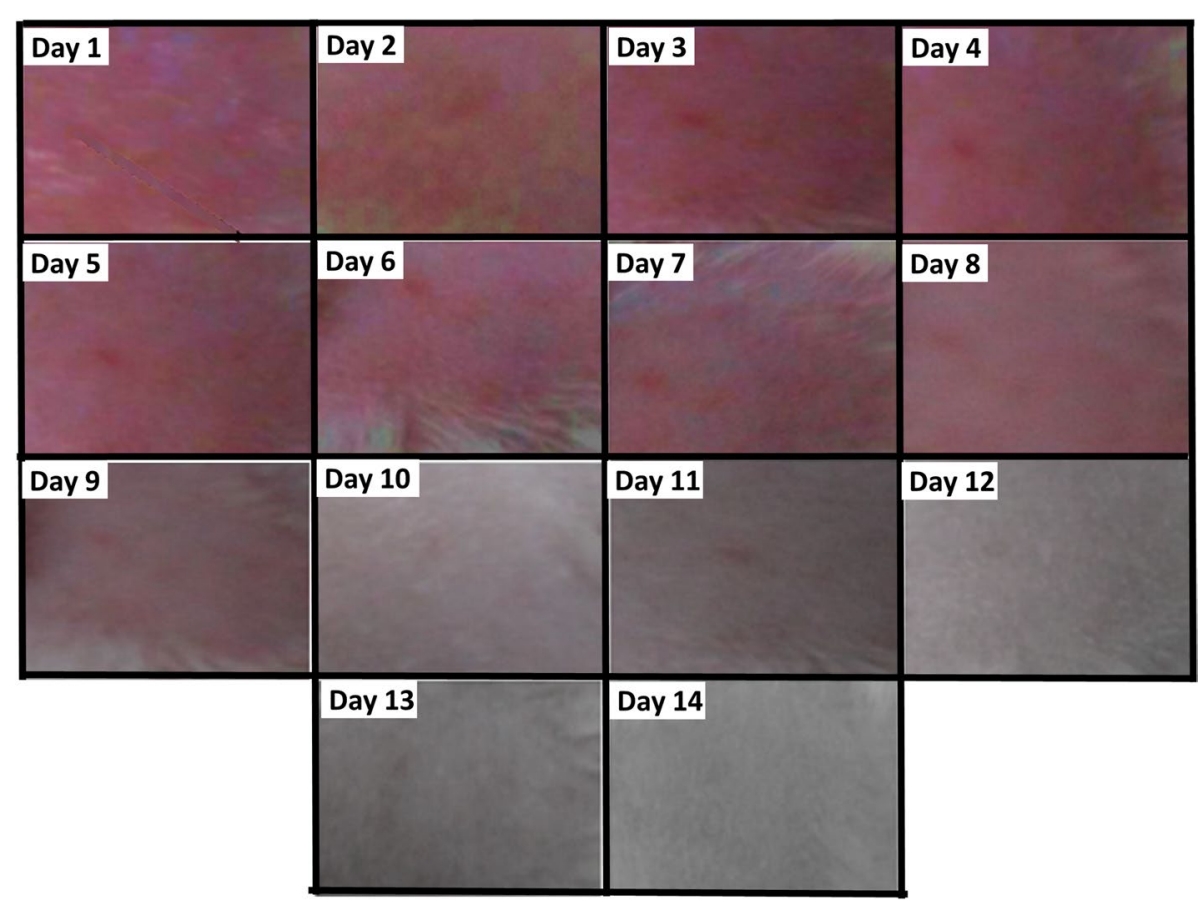

Fig. 3 Draize test of the optimized niosomal batch for checking any signs of irritation on the skin

Table 7 Ex vivo permeation studies of OZ (gamma oryzanol) gel and OZ niosomal gel

\begin{tabular}{llllll}
\hline & Drug content (\%) & $\begin{array}{l}\text { \% Drug diffused after } \\
\mathbf{6 0} \mathbf{m i n}\end{array}$ & $\begin{array}{l}\text { \% Drug diffused after } \\
\mathbf{1 2 0} \text { min }\end{array}$ & $\begin{array}{l}\text { \% Drug in donor } \\
\text { compartment }\end{array}$ & $\begin{array}{l}\text { \% Drug } \\
\text { retained after } \\
\mathbf{1 2 0} \text { min }\end{array}$ \\
\hline OZ gel & $96.5 \pm 1.5$ & $5.8 \pm 0.5$ & $7.7 \pm 1.2$ & $75.2 \pm 4.3$ & $13.60 \pm 2.1$ \\
OZ niosomal gel & $99.7 \pm 2.1$ & $17.3 \pm 0.9$ & $25.1 \pm 2.7$ & $3.2 \pm 0.1$ & $71.17 \pm 3.6$ \\
\hline
\end{tabular}

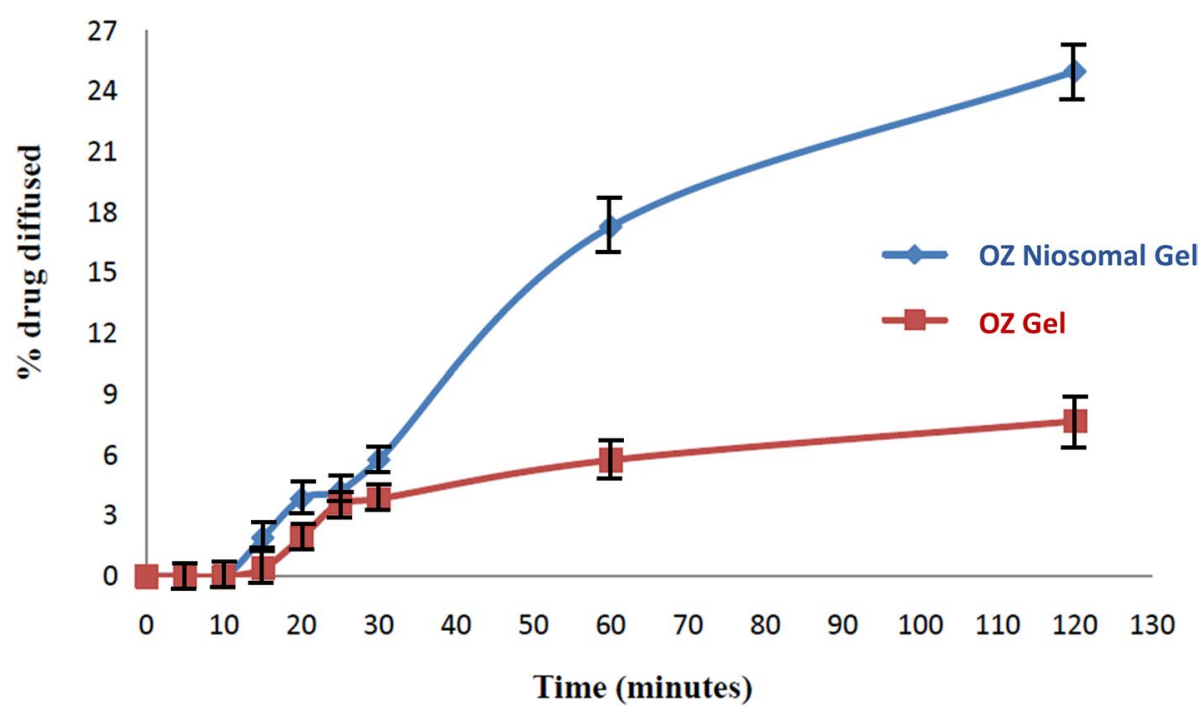

Fig. 4 Ex vivo permeation profile of (gamma oryzanol) OZ gel and optimized OZ niosomal gel 
Table 8 Stability results of OZ (gamma oryzanol) niosomal gel

\begin{tabular}{llllllll}
\hline Time point & Viscosity (cPs) & pH & Spreadability & $\begin{array}{l}\text { \% Drug diffused } \\
\text { after } \mathbf{6 0 ~} \mathbf{~ m i n}\end{array}$ & $\begin{array}{l}\text { \% Drug diffused } \\
\text { after 120 min }\end{array}$ & $\begin{array}{l}\text { \% Drug in donor } \\
\text { compartment }\end{array}$ & $\begin{array}{l}\text { \% Drug } \\
\text { retained after } \\
\mathbf{1 2 0} \text { min }\end{array}$ \\
\hline Initial & 8489 & $7.3 \pm 0.1$ & Very good & $17.3 \pm 0.9$ & $25.1 \pm 2.7$ & $3.2 \pm 0.1$ & $71.2 \pm 3.6$ \\
3 month & 7444 & $7.1 \pm 0.1$ & Good & $15.7 \pm 1.6$ & $23.8 \pm 6.1$ & $3.4 \pm 0.9$ & $72.5 \pm 4.3$ \\
\hline
\end{tabular}

in shape with very minimal aggregation. QbD approach was successfully applied for the proper treatment of all the variables. The risk assessment and control strategies were devised and implement accordingly. The optimized batch showed the average vesicle size of $196.6 \mathrm{~nm}$ and entrapment efficiency obtained was $78.31 \%$. Draize test revealed the potential of the niosomal gel for the effective delivery of $\mathrm{OZ}$ onto the skin without any adverse effects. Around 25\% of drug diffused into the receptor compartment whereas about $70 \%$ residual drug was remained in the $\mathrm{OZ}$ niosomal gel within $2 \mathrm{~h}$ of study, thus confirming better drug retention from the niosomal formulation which may be deemed effective in prolonged delivery of drug at the site of action. This formulation can reduce the frequency of drug administration and thus can help in improving the overall therapeutic outcome and patient compliance.

\section{Acknowledgements}

The authors would like to thank Institute of Pharmacy, Nirma University, Ahmedabad, for providing us all the facilities to carry out our research work.

\section{Authors' contributions}

Shital Butani contributed to the idea conceptualization and designed the study. Ankit Gotecha and Dolly Jetha were the primary scientists who executed the study. Harsh Shah performed the data analysis and is a major contributor in writing the manuscript. Harsh Shah, Amarjitsing Rajput, Adit Bariya, and Shital Panchal contributed ideas and information to the study and suggested revisions in during manuscript preparation. The authors read and approved the final manuscript.

\section{Funding}

Not applicable.

\section{Availability of data and materials}

The datasets used and/or analyzed during the current study are available from the corresponding author on reasonable request.

\section{Declarations}

\section{Ethics approval and consent to participate}

The animal protocol was approved by the Institutional Animal Ethics Committee (Protocol no. IP/PCEU/MPH/14-1/010). All animals were treated in accordance with the guidelines of the committee for CPCSEA.

\section{Competing interests}

The authors declare that they have no competing interests.

\section{Author details}

1 J-Star Research Inc., Cranbury, NJ 08512, USA. ²Department of Pharmaceutical Technology, Institute of Pharmacy, Nirma University, Ahmedabad, Gujarat 382481, India. ${ }^{3}$ Department of Pharmaceutics, Poona College of Pharmacy, Bharati Vidyapeeth Deemed University, Erandwane, Pune, Maharashtra
411038, India. ${ }^{4}$ Arihant School of Pharmacy Education and Research, Adalaj, Gandhinagar, Gujarat 382421, India.

Received: 17 September 2021 Accepted: 21 October 2021

Published online: 06 December 2021

\section{References}

Al Sabaa H, Mady FM, Hussein AK, Abdel-Wahab HM, Ragaie MH (2018) Dapsone in topical niosomes for treatment of acne vulgaris. Afr J Pharm Pharmacol 12(18):221-230

Bhaskaragoud G, Rajath S, Mahendra V, Kumar GS, Krishna AG, Kumar GS (2016) Hypolipidemic mechanism of oryzanol components-ferulic acid and phytosterols. Biochem Biophys Res Commun 476(2):82-89

Chaturvedi K, Gajera BY, Xu T, Shah H, Dave RH (2018) Influence of processing methods on physico-mechanical properties of ibuprofen/HPC-SSL formulation. Pharm Dev Technol 23(10):1108-1116

Code U, Law P. Code of Federal Regulations (CFR). Electronic version on< http://www.ecfr.gov/cgi-bin/ECFR. 2017.

Danaei M, Dehghankhold M, Ataei S, Hasanzadeh Davarani F, Javanmard R, Dokhani A et al (2018) Impact of particle size and polydispersity index on the clinical applications of lipidic nanocarrier systems. Pharmaceutics. 10(2):57

Das S, Wong AB (2020) Stabilization of ferulic acid in topical gel formulation via nanoencapsulation and $\mathrm{pH}$ optimization. Sci Rep 10(1):1-18

Elder D, Teasdale A (2017) ICH Q9 quality risk management. In: ICH Quality Guidelines: An Implementation Guide, pp 579-610

Geusens B, Strobbe T, Bracke S, Dynoodt P, Sanders N, Van Gele M et al (2011) Lipid-mediated gene delivery to the skin. Eur J Pharm Sci 43(4):199-211

Ghaderi S, Ghanbarzadeh S, Mohammadhassani Z, Hamishehkar H (2014) Formulation of gammaoryzanol-loaded nanoparticles for potential application in fortifying food products. Adv Pharm Bull 4(Suppl 2):549

Guideline IHT (2003) Stability testing of new drug substances and products. Q1A (R2), current step 4:1-24

Hamishehkar H, Rahimpour Y, Kouhsoltani M (2013) Niosomes as a propitious carrier for topical drug delivery. Expert Opin Drug Deliv 10(2):261-272

Hua S (2015) Lipid-based nano-delivery systems for skin delivery of drugs and bioactives. Front Pharmacol 6:219

Juliano C, Cossu M, Alamanni MC, Piu L (2005) Antioxidant activity of gammaoryzanol: mechanism of action and its effect on oxidative stability of pharmaceutical oils. Int J Pharm 299(1-2):146-154

Kozuka C, Yabiku K, Takayama C, Matsushita M, Shimabukuro M, Masuzaki H (2013) Natural food science based novel approach toward prevention and treatment of obesity and type 2 diabetes: recent studies on brown rice and y-oryzanol. Obes Res Clin Pract 7(3):e165-ee72

Raghavendra \& Kumar B (2021) Studies on kinetics of isomerization of gamma oryzanol at air-water interface. Thin Solid Films 138764:1-8

Lee LY (2016) Study of the photodegradation and photostability of anti-cancer drugs in different media towards the development of both new actinometers and liquid formulations

LezamaDávila CM (1999) Vaccination of C57BL/10 mice against cutaneous leishmaniasis. Use of purified gp63 encapsulated into niosomes surfactants vesicles: a novel approach. Mem Inst Oswaldo Cruz 94(1):67-70

Liang Y, Gao Y, Lin Q, Luo F, Wu W, Lu Q et al (2014) A review of the research progress on the bioactive ingredients and physiological activities of rice bran oil. Eur Food Res Technol 238(2):169-176

Lohcharoenkal W, Manosaroi A, Götz F, Werner RG, Manosroi W, Manosaroi J (2011) Potent enhancement of GFP uptake into HT-29 cells and 
rat skin permeation by coincubation with tat peptide. J Pharm Sci 100(11):4766-4773

Lowry GV, Hill RJ, Harper S, Rawle AF, Hendren CO, Klaessig F et al (2016) Guidance to improve the scientific value of zeta-potential measurements in NanoEHS. Environ Sci Nano 3(5):953-965

Manosroi A, Chutoprapat R, Abe M, Manosroi W, Manosroi J (2012) Transdermal absorption enhancement of rice bran bioactive compounds entrapped in niosomes. AAPS PharmSciTech 13(1):323-335

Marianecci C, Rinaldi F, Mastriota M, Pieretti S, Trapasso E, Paolino D et al (2012) Anti-inflammatory activity of novel ammonium glycyrrhizinate/niosomes delivery system: human and murine models. J Control Release 164(1):17-25

Mehta SK, Jindal N, Kaur G (2011) Quantitative investigation, stability and in vitro release studies of anti-TB drugs in triton niosomes. Colloids Surf B: Biointerfaces 87(1):173-179

Mezei M, Gulasekharam V (1982) Liposomes-a selective drug delivery system for the topical route of administration: gel dosage form. J Pharm Pharmacol 34(7):473-474

Moghassemi S, Hadjizadeh A (2014) Nano-niosomes as nanoscale drug delivery systems: an illustrated review. J Control Release 185:22-36

Muzzalupo R, Tavano L, Cassano R, Trombino S, Ferrarelli T, Picci N (2011) A new approach for the evaluation of niosomes as effective transdermal drug delivery systems. Eur J Pharm Biopharm 79(1):28-35

Nasr M, Mansour S, Mortada ND, Elshamy A (2008) Vesicular aceclofenac systems: a comparative study between liposomes and niosomes. J Microencapsul 25(7):499-512

Osborne R, Perkins M (1994) An approach for development of alternative test methods based on mechanisms of skin irritation. Food Chem Toxicol 32(2):133-142

Panchal SS, Patidar RK, Jha AB, Allam AA, Ajarem J, Butani SB (2017) Antiinflammatory and antioxidative stress effects of oryzanol in glaucomatous rabbits. J Ophthalmol 2017:1-9

Pardakhty A, Varshosaz J, Rouholamini A (2007) In vitro study of poxyethylene alkyl ether niosomes for delivery of insulin. Int J Pharm 328(2):130-141

Priprem A, Limsitthichaikoon S, Thappasarapong S (2015) Anti-inflammatory activity of topical anthocyanins by complexation and niosomal encapsulation. Int J Chem Mol Eng 9(2):142-146

Rajput AP, Butani SB (2019) Resveratrol anchored nanostructured lipid carrier loaded in situ gel via nasal route: formulation, optimization and in vivo characterization. J Drug Deliv Sci Technol 51:214-223

Rawal T, Mishra N, Jha A, Bhatt A, Tyagi RK, Panchal S et al (2018) Chitosan nanoparticles of gamma-oryzanol: formulation, optimization, and in vivo evaluation of anti-hyperlipidemic activity. AAPS PharmSciTech 19(4):1894-1907

Reena M, Krishnakantha T, Lokesh B (2010) Lowering of platelet aggregation and serum eicosanoid levels in rats fed with a diet containing coconut oil blends with rice bran oil or sesame oil. Prostaglandins Leukot Essent Fat Acids 83(3):151-160
Rodsuwan U, Pithanthanakul U, Thisayakorn K, Uttapap D, Boonpisuttinant K, Vatanyoopaisarn S et al (2021) Preparation and characterization of gamma oryzanol loaded zein nanoparticles and its improved stability. Food Sci Nutr 9(2):616-624

Shah H, Parikh D, Butani S (2014) Formulation development \& optimisation of milk dissolving tablets as novel paediatric dosage form. Int J Drug Formln Res 5:84-96

Shah HS, Chaturvedi K, Dave RH, Bates S, Haware RV, Morris KR (2020) New insights on warfarin sodium 2-propanol solvate solid-state changes using a multivariate approach. Cryst Growth Des 20(11):7328-7340

Shah HS, Chaturvedi K, Hamad M, Bates S, Hussain A, Morris K (2019) New Insights on solid-state changes in the levothyroxine sodium pentahydrate during dehydration and its relationship to chemical instability. AAPS PharmSciTech 20(1):1-10

Shah HS, Rubin RF, Lakhwani GR, DiGregorio R, Dave RH (2021) Stability of insulin detemir injection in different primary packaging systems at room temperature. J Pharm Pract 34(2):253-258

Sharma V, Anandhakumar S, Sasidharan M (2015) Self-degrading niosomes for encapsulation of hydrophilic and hydrophobic drugs: an efficient carrier for cancer multi-drug delivery. Mater Sci Eng C 56:393-400

Suh M-H, Yoo S-H, Lee HG (2007) Antioxidative activity and structural stability of microencapsulated $\gamma$-oryzanol in heat-treated lards. Food Chem 100(3):1065-1070

Tagne J-B, Kakumanu S, Nicolosi RJ (2008) Nanoemulsion preparations of the anticancer drug dacarbazine significantly increase its efficacy in a xenograft mouse melanoma model. Mol Pharm 5(6):1055-1063

Toyoda M, Hama S, Ikeda Y, Nagasaki Y, Kogure K (2015) Anti-cancer vaccination by transdermal delivery of antigen peptide-loaded nanogels via iontophoresis. Int J Pharm 483(1-2):110-114

Verma DD, Verma S, Blume G, Fahr A (2003) Particle size of liposomes influences dermal delivery of substances into skin. Int J Pharm 258(1-2):141-151

Zeb A, Qureshi OS, Kim H-S, Cha J-H, Kim H-S, Kim J-K (2016) Improved skin permeation of methotrexate via nanosized ultradeformable liposomes. Int J Nanomedicine 11:3813

Zeinali M, Abbaspour-Ravasjani S, Soltanfam T, Paiva-Santos AC, Babaei H, Veiga F et al (2021) Prevention of UV-induced skin cancer in mice by gamma oryzanol-loaded nanoethosomes. Life Sci 119759:1-15

Zhao Z, Moghadasian MH (2008) Chemistry, natural sources, dietary intake and pharmacokinetic properties of ferulic acid: a review. Food Chem 109(4):691-702

\section{Publisher's Note}

Springer Nature remains neutral with regard to jurisdictional claims in published maps and institutional affiliations.

\section{Submit your manuscript to a SpringerOpen ${ }^{\circ}$ journal and benefit from:}

- Convenient online submission

- Rigorous peer review

- Open access: articles freely available online

- High visibility within the field

- Retaining the copyright to your article

Submit your next manuscript at springeropen.com 